Original Article

\title{
Anemia as a Risk Factor for Acute Lower Respiratory Tract Infection in Children Below Five Years of Age
}

\author{
Shakya Henish, ${ }^{1}$ Singh Saurav, ${ }^{1}$ Lakhey Ashish, ${ }^{2}$ \\ 'Department of Pediatrics, KIST Medical College and Teaching Hospital, Lalitpur, Nepal \\ ${ }^{2}$ Department of Pathology, KIST Medical College and Teaching Hospital, Lalitpur, Nepal
}

\section{ABSTRACT}

\begin{abstract}
Introduction: Lower respiratory tract infection is a major cause of death in children in a developing country and anemia is found to be one of the commonest associated cofactors. This study was aimed to determine association of anemia in children with lower respiratory tract infections.

Materials and Methods: The retrospective study was done over a one-year period for children under 5 years of age, admitted in Pediatric Ward of a tertiary Hospital in Lalitpur. The study included 100 diagnosed cases of lower respiratory tract infections as per WHO criteria and 100 age and sex matched patients who did not have respiratory complaints as controls, excluding prematurity, chronic diseases, malnutrition and severe systemic illness. Appropriate clinical history, examination routine investigations like hemoglobin, peripheral smear, and Chest X-ray were included.
\end{abstract}

Results: The age distribution maximum children were in the age group of 3 months to 23 months with significant association with prevalence of both pneumonia ( $p$ value 0.005 ) and anemia ( $p$ value 0.002 ). Anemia was found to be a significant risk factor for LRTI ( $\mathrm{p}$ value $<0.001$ ) with odds ratio of 2.68 and $95 \%$ CI $(1.51-4.75)$.

Conclusions: Anemia was significantly found to be associated with lower respiratory tract infections and these children were found to be 2.68 times more susceptible to lower respiratory tract infections. Early diagnosis and prevention of anemia is thus important to reduce the incidence of lower respiratory tract infections in children.

Keywords: Anemia; Hemoglobin; Iron deficiency anemia; Infection; Lower respiratory tract
Copyright: This is an open-access article distributed under the terms of the Creative Commons Attribution 4.0 International License, which permits unrestricted use, distribution, and reproduction in any medium, provided the original author and source are credited.

\section{Correspondence:}

Dr. Henish Shakya, MD,

Department of Pediatrics,

KIST Medical College and Teaching Hospital,

Lalitpur, Nepal.

ORCID ID: 0000-0003-0117-9236

E-mail; henishshakya@gmail.com

Submitted: $28^{\text {th }}$ February 2018

Accepted: $2^{\text {nd }}$ April 2018

Published: $1^{\text {st }}$ June 2018

Conflict of Interest: None

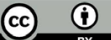

Citation: Shakya H, Singh S, Lakhey A. Anemia as a Risk Factor for Acute Lower Respiratory Tract Infection in children below five years of age. Nep Med J 2018; 1:5-8. DOI: 10.3126/nmj.v1i1.20390

\section{INTRODUCTION}

Lower respiratory tract infection (LRTI) is defined as a spectrum of illness which is basically the inflammation of airways and pulmonary tissue below the level of larynx. ${ }^{1}$ Pneumonia is one of the major cause of death in children accounting for $16 \%$ of all deaths in children under 5 years of age worldwide. ${ }^{2}$ It also accounts for the highest cause of morbidity in children under 5 years with an average of 5 to 6 episodes of LRTI per year. ${ }^{3}$ Although the occurrence of pneumonia is worldwide, it is most prevalent in South East Asia and Africa. ${ }^{2}$ In a developing country like Nepal, it ranks first on top 5 cause of death in under 5 age group. ${ }^{4}$ Pneumonia, though a lethal disease, is preventable in many aspects. Interventions like exclusive breastfeeding up to 6 months of age, boosting 
Table 1: Demographic variables for age and gender

\begin{tabular}{lccc}
\hline & & Case $(\mathbf{n}=\mathbf{1 0 0})$ & Control $(\mathbf{n}=\mathbf{1 0 0})$ \\
\hline Age & $<$ months & 6 & 10 \\
\hline & $\mathbf{3 - 2 3}$ months & 60 & 37 \\
& $\mathbf{2 4 - 5 9}$ months & 34 & 53 \\
Gender & & & \\
& Male & 56 & 58 \\
& Female & 44 & 40 \\
\hline
\end{tabular}

overall nutrition, timely vaccination and early management have played a pivotal role in decreasing both mortality and morbidity. ${ }^{2}$

Anemia is a clinical condition which occurs when there is decrease in the level of hemoglobin below the level insufficient to meet the body's physiologic need. Anemia is a major problem in all age groups, but the prevalence is higher in children and pregnant women. Global prevalence of anemia in children is around 47 percent. ${ }^{5}$ Prevalence of anemia in Nepal is 53 percent. ${ }^{6}$ Iron deficiency anemia is the most common between the ages of 6 months to 3 years of age. ${ }^{7}$ This is the age group where infections, most commonly pneumonia and gastroenteritis are more frequent. $^{2}$ Identifying risk factors and implementing preventive measures has always been a mainstay for a long-term disease management and control. In view of this background, this study is aimed to determine association of anemia in children with lower respiratory tract infection.

\section{MATERIALS AND METHODS}

A retrospective study was carried out for a period of 1 year from September 2016 to September 2017 in Pediatric department of KISTMCTH, Lalitpur. Permission was obtained from ethical committee. A total of 200 children (100 cases and 100 controls) admitted in the Pediatric ward were included in the study. Children under 5 years of age admitted with the diagnosis of LRTI with symptoms of fever, cough, tachypnea, chest retractions, and rhonchi or crackles on chest auscultation, as per the WHO criteria ${ }^{2}$ were included in the study. The cases were selected over a period of 1 year. The cases with incomplete data were excluded from the study. Age and sex appropriate children without any respiratory problems were taken as controls. Children with prematurity, congenital chest deformity, chronic diseases, severe systemic illness, children with PEM>grade III as per IAP guidelines, pulmonary tuberculosis and immune-compromised children were excluded from the study. Investigations included were hemoglobin, peripheral smear and a chest X-ray. Hemoglobin < $10 \mathrm{gm} \%$ was taken as anemia as per WHO criteria. Data entry was done using SPSS 21. Statistical analysis was done using Pearson chi-square test with special reference to following parameters: a) Age b) Gender c) Hemoglobin levels d) Past history of LRTI e) breastfeeding f) Peripheral smear examination and g) immunization status.

A $p$ value of $<0.05$ was considered as significant for statistical purpose. Odds ratio was calculated for anemia as a risk factor for LRTI. Binary Logistic Regression analysis was done for predictor variables.

\section{RESULTS}

A total of 200 children (100 cases and 100 controls) below 5 years of age were enrolled in the study. Among cases, $56 \%$ were males and $44 \%$ females whereas among controls, $58 \%$ were males and $42 \%$ females (Table 1). Among the demographic variables, age was statistically significant for both LRTI $(\mathrm{p}=0.005)$ and presence of anemia $(\mathrm{p}=0.002)$ (Table 2$)$, both predominant in 3 23 months age group. The main presenting symptoms and signs for cases were fever $(69 \%)$, crepitation (69\%), tachypnea $(60 \%)$ and cough $(50 \%)$ while for the controls; they were fever $(50 \%)$, vomiting $(45 \%)$, loose motions $(34 \%)$, facial puffiness $(16 \%)$ and convulsions (15\%). Infiltration was seen in chest x-ray in 43 patients (fig.1). There was no significant association of anemia with immunization status, breast feeding and past history of LRTI. The mean hemoglobin level was $9.24 \mathrm{gm} / \mathrm{dl}$ for case group and $10.43 \mathrm{gm} / \mathrm{dl}$ for control group (Table 3). Anemia was present in $66 \%$ cases and $36 \%$ controls. Categorical variable anemia was statistically significant $(\mathrm{p}=0.001)$ with odds ratio $(\mathrm{OR})$ of $2.681,95 \% \mathrm{CI}(4.75-1.51)$ and shows presence of anemia which increases the risk of acute LRTI by 2.68 times as compared to non-anemic patient (Table 4).

\section{DISCUSSION}

Acute lower respiratory tract is considered as one of the leading cause of mortality in the children under 5 years of age worldwide, accounting to $16 \%$ of deaths under 5 years of age. ${ }^{2}$ This is more prevalent in the developing country like ours. Several risk factors like low birth weight, poor socioeconomic status, unsanitary living conditions, poor nutrition, lack of exclusive breast feeding have been identified. ${ }^{4}$ Anemia or low hemoglobin status has also been stated as one of the risk factor. ${ }^{8}$ While most healthy children can fight the infection with their natural defenses, children whose immune systems are compromised are at higher risk of developing infections. ${ }^{2}$ Anemia potentiates this affect by weakening the natural defenses of the body. ${ }^{9}$

The most common affected age group was 3 months to 23

Table 2A: Prevalence of pneumonia with age

\begin{tabular}{lccccc}
\hline & & \multicolumn{2}{c}{ Age } & Total \\
\cline { 3 - 5 } & & $<$ months & $\mathbf{3 - 2 3}$ months & 24-59 months & \\
\hline Presence of Pneumonia & yes & 6 & 60 & 34 & 100 \\
& No & 10 & 37 & 53 & 100 \\
\hline Total & & 16 & 97 & 87 & 200
\end{tabular}

$\mathrm{p}$ value $=0.005$ 
Table 2B: Prevalence of pneumonia with age

\begin{tabular}{|c|c|c|c|c|c|}
\hline & & \multicolumn{3}{|c|}{ Age } & \multirow[t]{2}{*}{ Tota } \\
\hline & & $<2$ months & 3-23 months & 24-59 months & \\
\hline \multirow[t]{2}{*}{ Presence of Pneumonia } & yes & 2 & 58 & 48 & 108 \\
\hline & No & 14 & 39 & 39 & 92 \\
\hline Total & & 16 & 97 & 87 & 200 \\
\hline
\end{tabular}

$p$ value $=0.002$

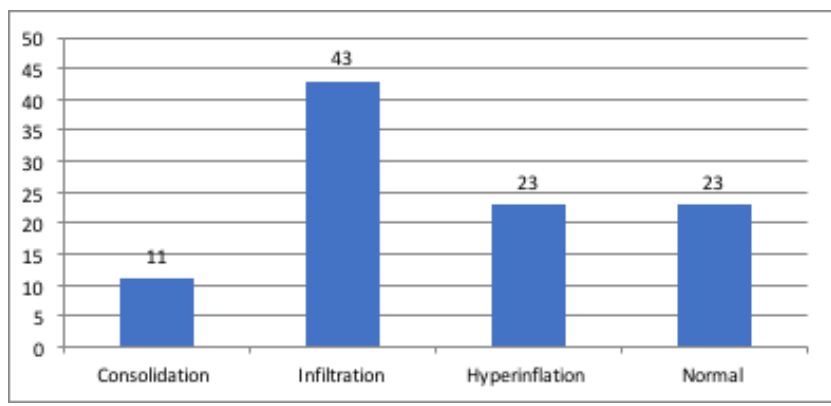

Figure 1: Chest X-ray findings

Table3: Hemogram of study population

\begin{tabular}{lcc}
\hline Hemogram & Case & Control \\
\hline Hb (Mean) & $9.24 \mathrm{gm} / \mathrm{dl}$ & $10.43 \mathrm{gm} / \mathrm{dl}$ \\
\hline Hb (Standard deviation) & 2.072 & 2.073
\end{tabular}

Hb value
$\begin{array}{lll}<10 \text { gm/dl } & n=66 & n=36 \\ >10 \text { gm/dl } & n=34 & n=64\end{array}$

Anaemia

\begin{tabular}{lll} 
Normocytic normochromic & $\mathrm{n}=40$ & $\mathrm{n}=57$ \\
\hline Microcytic hypochromic & $\mathrm{n}=45$ & $\mathrm{n}=11$ \\
Mixed & $\mathrm{n}=15$ & $\mathrm{n}=32$
\end{tabular}

months, this age group showed significant association with prevalence of both LRTI and anemia. This is comparable with other studies conducted by Malla T et al. ${ }^{7}$ and Ashraf $\mathrm{M}$ et al. ${ }^{12}$ The common involvement of this age group could be because of low hemoglobin level at this age group which is usually seen with poor or inadequate complementary feeding practices. Our study did not show any significant association with gender as

Table 4ultivariate Logistic Regression Analysis Showing Anetia a

among various studied populations. ${ }^{7,12-14}$ The higher number of male children may be attributed to the gender biasness for early admissions in the hospital seen in our society. The patients in our study had usual clinical presentation of ALRTI, and these findings were consistent with the study conducted by Malla et $\mathrm{al}^{7}$ and Roma K et al. ${ }^{14}$ Mean hemoglobin level was $9.24 \mathrm{~g} \%$ for cases and $10.43 \mathrm{~g} \%$ for controls which was consistent findings seen in other studies as well..$^{7-14}$ The peripheral smear however did not yield any significant association as compared to higher incidence of microcytic hypochromic anemia in other studies conducted by Malla et al. ${ }^{7}$ and Roma $\mathrm{K}$ et al. ${ }^{14}$ This may be attributed to the mixed findings in the peripheral smear. The association could have been clearly defined with an iron profile study. In our study, hemoglobin level less than $10 \mathrm{gm} \%$ was considered as anemia. Out of the 200 children, 108 children had anemia with 66 of ALRTI cases and 42 of non-ALRTI controls (OR 2.681, p value 0.001 ), signifying the 2.681 more likelihood of developing LRTI in children with anemia. This finding was consistent with the studies conducted by Malla et al (OR 4.6) ${ }^{7}$ and in Roma K et al. ${ }^{13}$ which shows 4.99 time susceptibility. Similar significance were also shown in other studies like OR- 4.63 in Ashraf $\mathrm{M}$ et al. ${ }^{12}$ and OR- 3.59 in Avhad Y et al. ${ }^{13}$ So, on comparing present study with other similar studies there was a significant association between anemia and LRTI. Thus, prevention of anemia and early diagnosis of anemia can play an important role to reduce the incidence of lower respiratory tract infection.

There are very few reports available in literature regarding the role of low hemoglobin level per se, as a risk factor for developing acute LRTI. Hemoglobin regulates oxygen and carbon dioxide transport and carries and inactivates nitric oxide. ${ }^{10}$ Therefore quantitative and/or qualitative reduction in hemoglobin, may adversely affect the normal functions. Alveolar macrophages obtain iron primarily from the RBC metabolism and plasma pool, and their function is may be hampered in iron deficient states ${ }^{11}$, and hence could be possible explanation for association of acute LTRI and deficient iron state and consequently iron deficiency anemia. $^{12}$

\section{Limitations of the study}

This study has many limitations; 1) This is a retrospective,

\begin{tabular}{|c|c|c|c|c|c|}
\hline & & \multicolumn{2}{|c|}{ Presence of anemia } & \multirow[t]{2}{*}{ Total } & \\
\hline & & yes & No & & \\
\hline \multirow[t]{2}{*}{ Presence of Pneumonia } & yes & 66 & 34 & 100 & \multirow{3}{*}{$\begin{array}{l}\mathrm{OR}=2.681 \\
95 \% \mathrm{CI}=(1.55-4.757) \\
\mathrm{P} \text { value }=0.001\end{array}$} \\
\hline & No & 42 & 58 & 100 & \\
\hline Total & & 108 & 92 & 200 & \\
\hline
\end{tabular}

Sensitivity: $66 \%$, Specificity: $58 \%$, PPV: $61 \%$, NPV: $63 \%$ 
hospital-based study, so prevalence in a community setting and effect of other variables may have been completely missed out. 2) The sample size of the study is small to come to a definite conclusion and warrants for a prospective study on a larger population. 3) Iron profile was not included in the study to see the prevalence of iron deficiency anemia, which contributes in the infection pathophysiology.

\section{REFERENCES}

1. Thomas P Green, Susanna A. McColley. Disorders of the lungs and lower airways. In: Richard E. Behrman, Robert Kleigman, Hal B. Jenson, ed. Nelson Text Book of Paediatrics. 17th ed. Philadelphia: Saunders; 2004. 1401pp

2. WHO fact sheet on pneumonia. [cited on 15th February 2018]. Available from: Crossref

3. Christi MJ, Tebruegge M, La Vincente S, Graham SM. Pneumonia in severely malnourished children in developing countries-mortality risk, etiology an validity of WHO clinical signs: A systematic review. Trop Med Int Health. 2009;14:1173-89. Crossref

4. Nepal demographic and health survey 2016. Population Division, Ministry of Health and Population Government of Nepal Kathmandu, Nepal. Annual Report 2016/2017:248. Crossref

5. WHO worldwide prevalence of Anaemia. [cited on 15th February 2018] Crossref

6. Nepal demographic and health survey 2016. Population Division, Ministry of Health and Population Government of Nepal Kathmandu, Nepal. Annual Report 2016/2017:230. Crossref

7. Malla T, Pathak OK, Malla KK. Is low hemoglobin level a risk factor for acute lower respiratory tract infections? J Nepal Pediatric Soci. 2010;30:1-7.

8. Ramakrishnan K, Harish PS. Hemoglobin Level as a Risk Factor for Lower Respiratory Tract Infections. Indian J Pediatr. 2006:73:10:881-3. Crossref

\section{CONCLUSIONS}

Anemia is a significant risk factor for Lower Respiratory Tract Infection. Prevention and early diagnosis of anemia is important to reduce the incidence of lower respiratory tract infection. Further studies need to be considered to consolidate this significance and other risk factors like low birth weight, lack of breast feeding, nutritional status, incomplete immunization, exposure to household and environmental smoke, should also be considered as possible risk factors.
9. Guyton \& Hall. Effect of hemoglobin to 'Buffer' the tissue PO2. Text Book of Medical Physiology. 11th ed. Philadelphia; Saunders. 2006: pp507-8.

10. Ganong WF. Gas transport between the lungs and the tissues. Review of Medical Physiology: 22nd ed. New York; Mc Graw-Hill, 2005. pp666-9.

11. Mateos F, Brock JH, Perez-Arellanoa JL. Iron metabolism in the lower respiratory tract. Thorax.1998;53:594-600. Crossref

12. Ashraf M, Wani J G, Ahmed J. Low Hemoglobin level a risk factor for acute lower respiratory tract infections in children. JCDR. 2014;8;4;PC01-PC03. Crossref

13. Avhad Y, Wade P, Ghildiyal RG. Anemia as a risk factor for lower respiratory tract infections (LRTI) in children. International Journal of Contemporary Medical Research 2016;3:3512-4.

14. Kma d R, Gupta V, Ahmada S, Singh R, Issranib R, Prabhuc N. Assessment of Anemia as a Risk Factor for Acute Lower Respiratory Tract Infections in Children: A Case-Control Study. Int J Clin Pediatr. 2015;4:149-53. Crossref 